\title{
Unusual localization of ganglion cyst: two case reports
}

\author{
Hasan Göçer*, Serdar Ulusoy, Alper Çıraklı, Mehmet Yunus Timurtaş, Nevzat Dabak \\ Department of Orthopaedics and Traumatology, Faculty of Medicine, Ondokuz Mayıs University, Samsun, Turkey
}

\begin{tabular}{|c|c|}
\hline \multicolumn{2}{|c|}{ ARTICLE INFO } \\
\hline \multicolumn{2}{|c|}{ Article History } \\
\hline Received & 14 / 08 / 2013 \\
\hline Accepted & $01 / 10 / 2013$ \\
\hline
\end{tabular}

\section{* Correspondence to:}

Hasan Göçer

Department of Orthopaedics and Traumatology, Faculty of Medicine,

Ondokuz Mayıs University

Samsun, Turkey

e-mail: drhasangocer@hotmail.com

\author{
ABSTRACT
}

Ganglion cysts are cystic lesions originating from the joint capsule or tendon sheath. They are the most common type of soft tissue tumors in hand, wrist and foot. They are more frequent at the age of 30-50 and women are more likely to be affected than men. Differential diagnosis includes lipoma, fibroma, osteoma, sarcoma, tuberculosis, rheumatoid tenosynovitis and aneurysm. Although most commonly found in hand and wrist, ganglion cysts may also occur in the dorsal surface of the foot. In this study, we evaluated two cases of ganglion cyst located in the plantar surface of the toe, a localization that has rarely been encountered in the literature. Pathology results supported our diagnosis of ganglion cyst and no recurrence was observed during 6-month follow-up.

J. Exp. Clin.Med., 2014; 31:103-105

\author{
Keywords: \\ Foot \\ Ganglion cyst \\ Surgical treatment \\ Toe
}

\section{Introduction}

Ganglion cysts are the soft tissue masses surrounded by dense connective tissue. It originates from joint capsule or tendon sheath. Capsule is filled with hyaluronic acid and other mucopolysaccharide-rich fluid (Liu et al., 1994). Ganglion cyst is most common at the age of 30-50 and among women (Akman et al., 2003). It is more common in hand, wrist and foot (Akman et al., 2003). Although, it shows differences with respect to the localization, the main complaints are pain and swelling. Ganglion cysts are called as intraosseous, subperiosteal and soft tissue cysts according to their locations and the anatomical regions that they originate (Akman et al., 2003). The treatment options include follow-up, aspiration, sclerotherapy and surgical excision (Thornburg, 1999). Cyst recurrence is the most common complication despite the treatment (Park et al., 2002). In two cases presented here, ganglion cysts localized in the plantar surface of the toe, an unusual site of occurrence, are discussed.

\section{Case presentation}

Case 1

A 45-year-old female patient weighing $77 \mathrm{~kg}$ presented with a four-month history of palpable swelling in the lower and front part of her left toe and the pain especially increases when she wears shoes. On physical examination, a palpable soft tissue mass ( $3 \mathrm{~cm}$ in diameter) located in the distal plantar surface of the toe was detected. No erythema and sensitivity was observed in the site of occurrence. No pathology was detected on X-ray examination. Magnetic Resonance Imaging (MRI) showed a $2 \times 3 \mathrm{~cm}$ cystic lesion (hypointense on $\mathrm{T} 1$ and hyperintense on T2) in the distal phalanx plantar surface of left toe extending the lateral. Images indicated ganglion cyst. Pathological result of the surgical excision-performed patient was interpreted as ganglion cyst. The patient had no postoperative complication. No recurrence was observed during 6-month follow-up.

\section{Case 2}

A 52-year-old, female patient weighing $80 \mathrm{~kg}$ presented with a three-month history of palpable swelling in the lower and front part of her left toe and the pain especially increases when she wears shoes. On physical examination, a palpable soft tissue mass $(2 \mathrm{~cm}$ in diameter) located in the distal plantar surface of the toe was detected (Fig. 1). No erythema 
and sensitivity was observed in the site of occurrence. No pathology was detected on X-ray examination. MRI showed a $2.5 \mathrm{~cm}$ lobule contoured septal cystic mass (hypointense on $\mathrm{T} 1$ and hyperintense on T2) in the plantar surface and terminal phalanx of left toe (Fig. 2). Images indicated ganglion cyst. Mucous liquid was observed during surgical excision (Fig. 3). Pathological result of the surgical excision-performed patient was interpreted as ganglion cyst. The patient had no postoperative complication. No recurrence was observed during six-month follow-up.

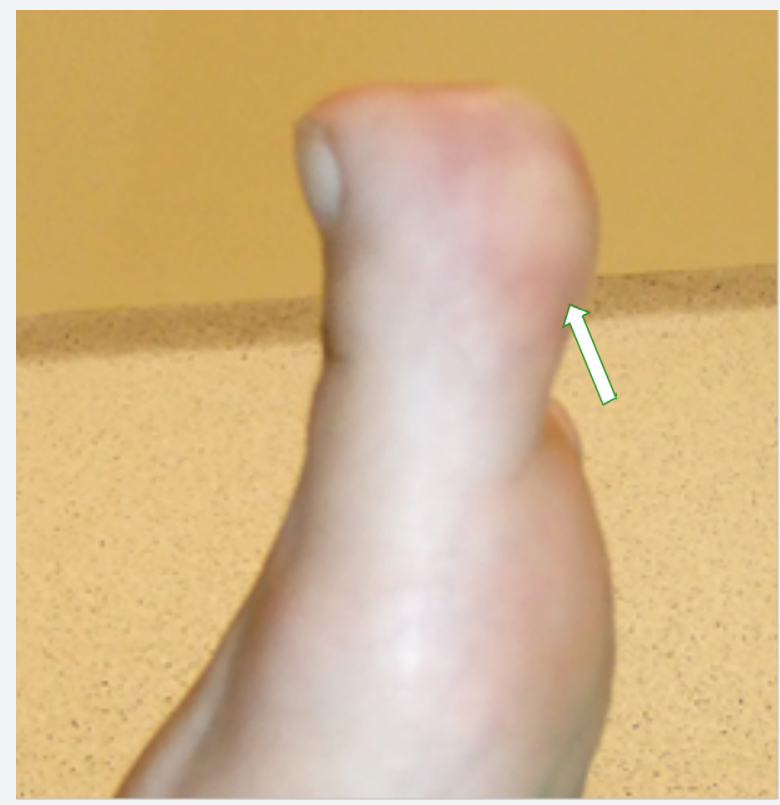

Fig. 1. Arrow shows swelling.

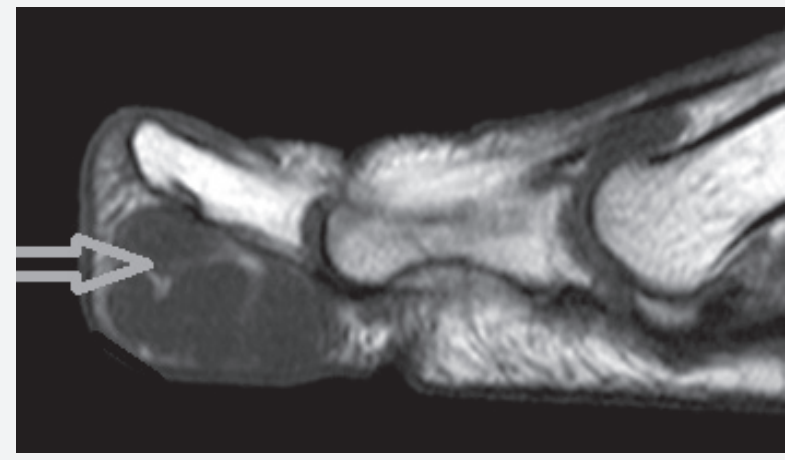

Fig. 2. Arrow shows lobule contoured septal cystic mass at magnetic resonance imaging.

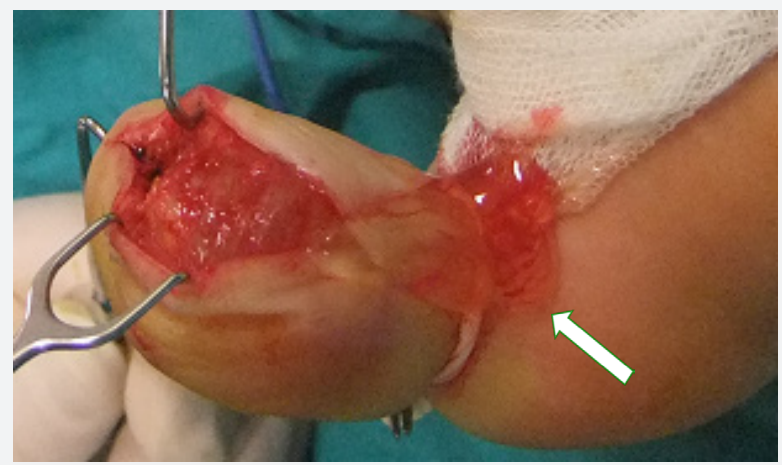

Fig. 3. Arrow shows mucous liquid.

\section{Discussion}

Ganglion cysts are most common at the age of 30-50 and women are more likely to be affected than men (Akman et al., 2003). Its etiology remains obscure (Barnes et al., 1964). Micro traumas and underlying joint pathologies are thought to be important factors (Haber et al., 2002). Ganglion cyst is a cystic structure filled with mucopolysaccharide matrix in connective tissue sheath. Cyst may be periosteal, mucoid degeneration and congenital origin (Liu et al., 1994). In our cases, toe-localized cysts may be attributed to the micro traumas resulting from inappropriate shoe choice. Ganglion cysts often originate from joint capsule or tendon sheath. Rarely, they can also result from tendon fibers. Our cases had ganglion cyst originating from tendon of the flexor hallucis longus muscle in the plantar surface of the toe. The distinctive feature of our study is the atypical localization of the cysts. Ganglion cysts are more common in hand and wrist and less frequent in the proximal tibiofibular joint, shoulder, foot and ankle (Akman et al., 2003). Plantar surface of the toe localization that has rarely been encountered in the literature (Rozbruch et al., 1998). The differential diagnosis includes tuberculosis, rheumatoid tenosynovitis, lipoma, fibroma, osteoma, sarcoma, and aneurysm. MRI provides useful information in determining the anatomy of the soft tissue tumors and definitive diagnosis according to the signal characteristics. On T2-weighted and gradientecho examinations, collections characterized by lobular, multiseptated, hyperintense signal increase covering whole lesion are ganglion cyst-specific (Akman et al., 2003). Many researchers have the opinion that ultrasound (US) and MRI examinations are extremely useful in the differentiation of ganglion cysts from other soft tissue masses (Abiezzi and Miller, 1995). In our case, the diagnosis was established as result of the MRI examination in accordance with the literature. Treatment options include conservative and surgical methods. In symptomatic cases such as pain, numbness and aesthetic deformity, the definitive treatment involves surgical excision. Due to the atypical localization of ganglion cysts, difficulty in needle aspiration and the risk of recurrence, surgical excision is recommended (Park et al., 2002). In some cases, recovery or regression of the cysts without any treatment has been reported. Therefore, surgical treatment is recommended only in symptomatic cases and those resistant to conservative therapy (Thornburg, 1999). High incidence of recurrence (0-40\%) has been reported in the literature (Satku and Ganesh, 1985; Haber et al., 2002). The high recurrence rates after total excision may be associated with the improper excision (Satku and Ganesh, 1985). Surgical excision was performed to each of our cases due to their complaints. The clinical and radiological recurrence was not observed during six month-follow-up.

Because unusual localization of ganglion cysts, albeit rarely, may also occur, it should be considered in the differential diagnosis. We are of the opinion that total surgical resection is helpful in symptomatic cases with regard to patient relief and reducing recurrence. 


\section{REFERENCES}

Abiezzi, S.S., Miller, L.S., 1995. The use of ultrasound for the diagnosis of soft tissue masses in children. J Pediatr. Orthop. 15, 566-573.

Akman, S., Gur, B., Sulun, T., Aksoy, B., 2003. Kalça eklem kapsülü kaynaklı ganglion kisti ve cerrahi sonucu: Olgu sunumu. Acta. Orthop. Traumatol. Turc. 36, 76-78.

Barnes, W.E., Larsen, R.D., Posch, J.L., 1964. Review of ganglia of the hand and wrist with analysis of surgical treatment. Plast. Reconst. Surg. 34, 570-578.

Haber, L.H., Waanders, N.A, Thompson, G.H., Petersilge, C., Ballock, R.T., 2002. Sternoclavicular joint ganglion cysts in young children. J. Pediatr. Orthop. 22, 544-547.

Liu, S.H., Osti, L., Mirzayan, R., 1994. Ganglion cysts of the ACL: A case report and review of the literature. Arthroscopy. 10, $110-112$.

Park, S., Yoshimura, K., Kawasaki, Y., 2002. Phenol cauterization for ganglions of the hand, wrist and foot: A preliminary report. Ann. Plast. Surg. 48, 582-585.

Rozbruch, S.R., Chang, V., Bohne, W.H.O., Deland, J.T., 1998. Ganglion cysts of the lower extremity: An analysis of 54 cases and review of the literature. Orthopedics. 21, 141-148.

Satku, K., Ganesh, B., 1985. Ganglia in Children. J. Pediatr. Orthop. 5, 13-15.

Thornburg, L.E., 1999. Ganglions of the hand and wrist. J. Am. Acad. Orthop. Surg. 7, 231-238. 